\title{
GÊNERO NA INFÂNCIA: ANÁLISE DO FILME “LA VIE IN ROSE” COMO INSTRUMENTO PEDAGÓGICO EM EDUCAÇÃO SEXUAL
}

\author{
Aline Ariana Alcântara ANACLETO ${ }^{1}$ \\ Ana Claúdia Bortolozzi MAIA ${ }^{2}$
}

\begin{abstract}
RESUMO: O objetivo deste trabalho foi analisar as questões de gênero na sexualidade infantil por meio da narrativa midiática do filme $L a$ Vie in Rose, que apresenta os temas da transexualidade, homossexualidade, identidade de gênero, discriminação social e vínculos familiares. A partir das questões teóricas sobre sexualidade na infância e a construção de gênero, utilizando-se da análise de conteúdo, elegeu-se na narrativa do filme as seguintes categorias para discussão: (a) identidades sexuais: o masculino e o feminino, (b) o gênero patológico e a heteronormatividade, (c) educação sexual oferecida pela familiar e a socialização sexista, (d) o preconceito diante da diversidade sexual. O modo como o filme apresenta essas questões pode sensibilizar o espectador para questionamentos e reflexões sobre o tema e, nesse sentido, a análise do filme pode ser utilizada como um instrumento pedagógico por educadores que almejem refletir criticamente sobre questões referentes à sexualidade humana no campo da Educação Sexual.
\end{abstract}

PALAVRAS-CHAVE: Gênero. Sexualidade infantil. Recurso pedagógico.

\section{Introdução}

Sexualidade Infantil e Questões de Gênero: questões teóricas e conceituais

A sexualidade humana caracteriza-se como um fenômeno multideterminado e é um tema atualmente de destaque e interesse na área da Educação, envolvendo aspectos que vão além de sua dimensão biológica, isto é, aspectos psicológicos e sociais. A Sexualidade representa uma parte da personalidade individual do sujeito a partir da construção histórica e cultural em que ele se desenvolve, isto é, o modo subjetivo e particular com o que as pessoas expressam sua sexualidade envolve a influência do contexto social (MAIA, A. C., 2001). Por esta razão, é

\footnotetext{
1 Mestranda em Psicologia do Desenvolvimento e Aprendizagem. UNESP - Universidade Estadual Paulista. Faculdade de Ciências - Pós-Graduação em Psicologia do Desenvolvimento e Aprendizagem. Bauru - SP - Brasil. 17033-360 - aa_anacleto@hotmail.com

${ }^{2}$ UNESP - Universidade Estadual Paulista. Faculdade de Ciências - Departamento de Psicologia - Grupo de Estudo e Pesquisas "Sexualidade, Educação e Cultura" - GEPESEC - Programa de Pós Graduação em Psicologia do Desenvolvimento e Aprendizagem. Bauru - SP - Brasil. 17033-360 - aclaudia@fc.unesp.br
} 
preciso investir nos aspectos educativos que possam contribuir na formação da sexualidade em que se respeite a diversidade e as múltiplas manifestações do erotismo humano.

A sexualidade é inerente ao ser humano e desde os trabalhos de Sigmund Freud, a ciência psicológica tem contribuído para divulgar o quanto é importante a postura dos educadores adultos na educação sexual das crianças. Com seu texto "Três Ensaios Sobre a Teoria da Sexualidade", Freud inaugura a idéia de que as crianças também possuem sexualidade e procuram obtenção de prazer por meio de zonas erógenas e retira a sexualidade da vinculação estritamente genital ampliando sua manifestação e sua estruturação individual e social (MAIA, A. C.; MAIA, A. F. 2005).

A sexualidade, então, não pode ser entendida distante das normas sociais e culturais que a significam e lhe atribuem sentido, de modo que ela é conhecida, reproduzida e reformulada pelos discursos sobre a sexualidade, chamados de processo de educação sexual, que segue regras e normas sociais (MAIA, A. C., 2001).

O processo de educação sexual considera muitas ações, entre elas se encontra o pensar sobre a articulação entre gênero e infância e, assim, pensar em como a criança apreende a concepção do que é ser menino e do que é ser menina, já que a sociedade ao traçar a definição do feminino e do masculino, mesmo que subjetivamente, também traça estereótipos que se multiplicam e se cristalizam. Dessa maneira, a oposição do binário masculino/feminino é reproduzida socialmente e, em muitos casos, é tomado como verdade única no momento de pensar o conceito de gênero masculino e feminino (LOURO, 1999).

A construção do conceito de gênero e sua formação no indivíduo ocorrem por meio das dinâmicas de relações sociais entre os sujeitos, considerando este como um ser cuja totalidade é formada pelo corpo, pelo intelecto, pela emoção, pelo eu em contato com outro corpo; o ser humano é formado pelas relações interpessoais marcadas por contradições de gênero, classe, raça e etnia (SAFFIOTI, 1992). Para Saffioti (1992) as relações de gênero entre os sujeitos refletem as próprias concepções de gênero que estes possuem internalizadas. Cada sujeito configura uma identidade pessoal pelas relações com os outros e com o mundo objetivo e esta identidade se apóia na concepção que se forma por meio do pertencimento ou não a determinado gênero.

A idéia do que é ser feminino e do que é ser masculino e suas implicações na sexualidade, em que todos os seres humanos são enquadrados, formam um sistema de gênero em uma dada cultura. Sistema este simbólico, com significações que relacionam aspectos do sexo masculino e 
feminino a conteúdos que formam o gênero masculino e feminino (CARLOTO, 2001). Pode-se perceber que o gênero, conforme afirma Bonetti (2003), como uma categoria analítica, articula significantes construídos historicamente e que são dados por determinada cultura. Estes são internalizados pelos sujeitos, os quais lhe atribuem determinados sentidos. O que de certa forma, implica na atribuição de valores culturais as categorias de gênero, na tentativa de legitimar o que se tem como verdade e dar sentido ao que se percebe como diferente do já pressuposto.

No mundo infantil a construção da concepção de gênero e da identidade sexual não se faz diferente. É por meio da história, da cultura e da simbolização que a criança vai construindo sua idéia do que é ser menino e do que é ser menina. Em suas vivências cotidianas que criam e simbolizam a noção do que é esperado, permitido e consentido para cada categoria de gênero e para as relações que se devem estabelecer entre elas. Aqui se encontra o papel da educação sexual na formação da sexualidade infantil.

O objetivo deste trabalho foi analisar as questões de gênero na sexualidade infantil por meio da narrativa midiática do filme Minha Vida em Cor de Rosa, cujo título original é La vie in Rose, dirigido por Alain Berliner, a partir da discussão de temas como a transexualidade, homossexualidade, identidade de gênero, discriminação social e preconceito bem como vínculos entre os membros familiares, tendo como eixo central a sexualidade infantil e a construção de gênero. Pretende-se articular, portanto, a teoria da sexualidade infantil com a narrativa buscando, de forma analítica, descrever elementos que ilustrem que a análise do filme pode ser utilizada como um instrumento pedagógico por professores e outros educadores que almejem refletir criticamente sobre questões referentes à sexualidade humana.

\section{Procedimentos Metodológicos}

Objeto de análise: o filme "Minha vida em Cor de Rosa”

Segundo Fernandes e Siqueira (2006) o cinema é um meio expressivo muito importante para evidenciar cenas cotidianas, dando sentido e significado a elas e, portanto, contribui na construção de identidades sociais. O discurso cinematográfico pode, segundo os autores, ser um instrumento que reproduz padrões sobre feminilidades/masculinidades. Mas pode, também, ser um veículo para criticar esses padrões normatizadores de gênero. 
Partindo dessa premissa, elegemos para análise o filme Minha Vida em Cor de Rosa, La Vie En Rose em seu título original, dirigido por Alain Berliner, lançado no ano de 1997 e protagonizado por Georges Du Fresne, no papel do pequeno Ludovic. Conta, em seus 110 minutos de duração, a história de um menino de sete anos de idade, Ludovic, irmão de outros dois meninos e uma menina, que juntamente com a mãe Hanna e o pai Pierre, configuram a família Fabre, tradicional burguesia de uma pequena cidade Francesa. O menino Ludovic tem um corpo biológico anatômico e funcional masculino e, no entanto, aos poucos revela a consciência de ser uma menina e a percepção de desejos eróticos por um garoto vizinho, Jerome, filho do chefe de seu pai. A narrativa envolve a expressão de gênero diferenciada do menino em relação aos seus irmãos e à comunidade em geral (vizinhos, escola) o que, no começo é tolerada pela família e depois se torna alvo de conflitos entre os membros da família e da comunidade.

\section{Procedimento de Análise}

A narrativa do filme foi transcrita em texto elencando os elementos centrais de análise, a partir dos eixos teóricos: sexualidade na infância e construção do gênero. Tendo como pano de fundo as questões teóricas, a análise consistiu em destacar e comentar agrupamentos temáticos, por meio da análise de conteúdo proposta por Bardin (1977), que relacionassem a narrativa midiática com a teoria para direcionar uma discussão sobre diversidade de gênero na infância. A partir daí, as seguintes categorias foram comentadas: identidades sexuais: o masculino e o feminino, patologização de gênero a partir da categoria heteronormativa, educação sexual familiar e socialização sexista e, ainda, o preconceito diante da diversidade sexual.

\section{Resultados}

As experiências de socialização da criança, que ocorrem primeiramente na família e depois na escola, são muito importantes no cotidiano infantil e favorecem a possibilidade de que as crianças reconheçam as diferenças sexuais e que despertem nelas a compreensão do que é ser menina e ser menino. Essas diferenças sexuais são constituídas biologicamente, mas configuramse em relações de gênero quando são mediadas pela cultura. No filme, a família e a escola de Ludovic não propiciavam a ele uma compreensão da distinção entre menino e menina. Suas 
experiências cotidianas não pautavam a distinção e nem apontavam as diferenças.

Assim, a interpretação de Ludovic sobre suas experiências ligadas às relações de gênero, tanto em casa quanto na escola, se fazia de acordo com seu desejo de ser uma menina. Isso fica claro na cena em que ele acorda com dores na barriga e as interpreta como cólicas menstruais, como as de sua irmã, acreditando que suas "regras” vieram e que então seria uma menina. O que acaba influenciando na construção de sua identidade e dos papéis que esta exerceria. Fato este, bem exemplificado, pelo desejo de Ludovic de se casar com Jerome, o filho do patrão de seu pai, e exercer um papel de esposa, de mãe, de mulher com esse menino. Ludovic reproduz tão explicitamente esse desejo que imita os comportamentos e as atitudes de sua mãe e de sua avó, o que pode ser visto na cena em que os três dançam juntos na festa que inicia o filme e também na cena em que Ludovic e Jerome brincam de casamento.

As simbolizações que Ludovic faz dos comportamentos que observa remetem para a satisfação de seus desejos, de modo que, somente depois que é levado à psicóloga e ouve seus pais dizendo que é um menino é que toma consciência de que faz parte desse gênero. Curiosamente, até então, a socialização familiar não tinha sido capaz de embutir como autoconsciência de seu pertencimento ao masculino. Dessa relação dos pais com a psicóloga, que marca o comportamento do menino como problemático e patológico (levar ao psicólogo para “diagnosticar a questão” e “curar”), é que Ludovic começa a perceber os transtornos causados por suas atitudes e numa tentativa de aliviar o sofrimento dos pais, passa a observar e a imitar os comportamentos dos seus irmãos e dos meninos da escola, como, por exemplo, jogar jogos de luta e tentar beijar uma garota. Nesta cena, a menina aparece de rosa e Ludovic de azul, o que dá idéia de que eles estão dentro dos padrões afirmados e consentidos pela sociedade.

Como suas tentativas não são bem sucedidas, Ludovic não consegue compreender seus desejos e não se sente à vontade em copiar os papéis masculinos; ao mesmo tempo, sua família e a escola não lhe possibilitam nenhuma explicação sobre suas dúvidas, o que intensifica um conflito interno em Ludovic que até então não aparecia; ele próprio se pergunta a qual gênero pertence, tendo dificuldades de se reconhecer menino ou menina. Ao questionar sua irmã mais velha sobre isso ela busca livros de biologia para explicar a ele sobre os pares de cromossomos; ser menino é ter XY e ser menina é ter XX. Diante da explicação, Ludovic ao invés de se adaptar à explicação e reconhecer-se “desviante da norma”, elabora de modo fantasioso um argumento que justificaria seu desejo, isto é, julga-se um "menino-menina” que a qualquer momento vai 
receber de Deus seu outro $\mathrm{X}$ que foi perdido. Ao ouvir isso sua mãe acredita que ele está progredindo em mudanças, porém ela não lhe dá nenhuma outra explicação, não esclarecendo que Deus não irá lhe providenciar outro X para que se torne uma menina. O silêncio da mãe parece mais atender a sua ansiedade em resolver a questão do que encarar que para o menino, a consciência de pertencimento do sexo oposto parecia imutável.

A omissão dos pais em relação ao diálogo sobre gênero faz com que Ludovic não entenda o espanto, a estranheza de seus pais e dos seus vizinhos diante de suas atitudes. Para ele, o seu desejo de ser menina é natural e por isso ele acredita que um dia se tornará uma mulher de fato, o que não acontece. Diferente da reação das pessoas que estão a sua volta, que são intolerantes frente as suas ações. Isso fica claro na cena em que Ludovic corre para sua irmã assustado com o fato de achar que vai para o inferno, depois de Jerome, na sala de aula, pedir para sentar longe de Ludovic, porque senão iria para o inferno. Essa situação somada ao desejo de ser menina contribui para que Ludovic acredite que Deus irá trazer lhe seu outro X e invista, cada vez mais, nessa idéia de mudança de sexo, o que caracteriza sua transexualidade.

Percebe-se em Ludo o discurso típico da transexualidade, que leva a convicção do pertencimento ao sexo oposto e considera como um erro da natureza o pertencimento ao sexo anatômico, buscando convencer a todos sobre a necessidade de reparação deste erro (RAMSEY, 1998; VERDE; GRAZIOTTIN, 1997; VIEIRA, 1996). Para Rinaldi e Bittencourt (2003, p.6), a problemática transexual se dirige para a relação que o sujeito estabelece com o seu sexo anatômico e com sua identidade de gênero, já que a integração de sua sexualidade se dá pelo reconhecimento simbólico que este faz, o que parece dar significado ao que o sexo biológico apresenta como real. Isso, segundo os autores, explica o fato de que o sujeito transexual “[...] não pôde ou não aceitou colocar-se do lado masculino ou do lado feminino, no que diz respeito ao seu gozo [...]”, o que lhe confere uma difícil relação entre sua identidade de gênero e seu sexo anatômico.

Essa dificuldade é encontrada e vivenciada por Ludovic, que ao decorrer da história, nos apresenta uma incoerência entre o sexo e o gênero (ARÁN, 2006), construída por diversas maneiras e demonstrada pelo seu desejo de ser uma menina, ao se vestir de vestido e usar brincos, ao dançar como a personagem da novela, ao se apaixonar por um garoto, ao usar os cabelos compridos e ao acreditar que um dia se tornará uma garota.

Não se pretende enfocar e discutir a transexualidade em si, o que, segundo a literatura, é 
revelada ainda na infância e não se constitui apenas em uma questão de orientação afetiva e sexual homoerótica. No entanto, somado ao fato da transexualidade o diretor acrescenta em sua história a paixão de Ludovic por Jerome. No caso da transexualidade, uma vez que a identidade de gênero do garoto seria feminina a paixão pelo vizinho revelaria sua orientação heterossexual, todavia, é a compreensão social da suposta homossexualidade do garoto que indica, além da transexualidade, o incômodo dos familiares e dos vizinhos. Tudo isso causa grandes desentendimentos entre Ludovic e as pessoas a sua volta, já que para eles os comportamentos de Ludovic são atípicos e destoantes dos padrões sociais aceitos e valorizados, o que causa vergonha e conflito para a família de Ludovic que lidam com o sentimento de anormalidade.

As famílias, em sua maioria, vivem e reproduzem a crença de que a sexualidade humana é biológica, deixando de entendê-la como uma construção social, cultural e histórica. A família, assim, produz e reproduz o preconceito contra a homossexualidade, de modo que, a educação familiar se orienta no sentido de evitar o diferente. No filme isto fica muito claro nas atitudes de recriminação da família frente aos comportamentos de menina de Ludovic relacionando isso a uma “orientação sexual desviante”. Os pais usam estratégias, conscientes ou inconscientes, para reforçar o padrão sexual instituído e legitimado, a heterossexualidade. Quando há a percepção de aspectos que destoam dos padrões sociais estabelecidos, os pais possuem grande dificuldade em enfrentar as diferenças. A crença de que os comportamentos são ensinados e garantem a heterormatividade baseia a luta da família em “ajudar” e a "normatizar” o comportamento do menino. Uma cena que exemplifica isso é quando a mãe de Ludovic corta o seu cabelo, como se a ação fosse eliminar o desejo de ser e se transformar em uma menina. Do mesmo modo, o pai utiliza como uma estratégia educativa para reforçar e legitimar a masculinidade do menino dizendo a ele para "passarem mais tempo juntos”, isto é, expondo conscientemente o garoto aos modelos normativos de masculinidade, como jogar futebol, por exemplo, que na concepção dos pais garantiram aos outros filhos a heterossexualidade desejável. O pai insiste no jogo, mesmo percebendo as dificuldades e a falta de vontade de Ludo.

A dificuldade da família Fabre fica expressa durante grande parte do filme, porque em vários momentos os pais, os irmãos e a avó ficam em silêncio diante de Ludovic, sem saber dar respostas ou explicações a ele. Isso gera conflitos na família como um todo. São o silêncio e a imobilidade que norteia o comportamento dos familiares diante do "diferente", diante dos comportamentos de Ludovic que fugiam dos padrões normativos internalizados neles próprios. 
Percebe-se a grande dificuldade de todos da família na discussão sobre sexualidade e suas implicações para o desenvolvimento de Ludovic.

É importante comentar que o julgamento do comportamento atípico do menino é julgado como indecente e indesejável. Por se tratar de criança a idéia de que ele ocorreria de modo proposital e maldoso fica desvanecido e dá lugar a compreensão de patologia, mediado pelos sentimentos de afeto em relação ao menino. Na verdade, percebe-se que a concepção geral, inclusive dos pais, é de que a “diferença” de gênero percebida é indesejável e desvantajosa: tratase do estigma sobre o desviante que inclusive se estende a toda a família, como bem discutiu Goffman (1988).

Durante o filme a história demonstra como a família fica presa as convenções e as regras sociais, que chega a não perceber que eles próprios não compreendem as atitudes e os desejos de Ludovic, reproduzindo o preconceito e a estranheza dos vizinhos, o que causa sofrimento e mais conflitos ao garoto. A solução que a família encontra, diante de várias ações fracassadas em normatizar as atitudes e os desejos do menino é recriminar todas as ações dele que desviam da norma e, num extremo, mudarem de cidade com o objetivo de começar uma vida nova, longe dos olhares preconceituosos dos vizinhos.

A resolução que o diretor dá para o final da história, com a mudança da família Fabre, fica evidente na cena em que o vestido rosa, o qual Ludo aparece pela primeira vez no filme, voa da mala, quando a família está indo embora. A cena pode indicar que juntamente com o vestido, o desejo de Ludovic, de ser menina, também ficará para trás e, assim, satisfazer a vontade da família de que com a mudança, Ludovic também mude e aceite que é um menino.

Outro ponto interessante referente ao fim da história está no momento em que a mãe de Ludovic fantasia, assim como ele, e entra no mágico mundo da boneca. Ela faz isso ao se deparar com uma situação que pode apontar que seu filho, na nova casa, irá novamente a ter atitudes de menina, fora dos padrões sociais. É como se ela estivesse vivenciando o desejo de seu filho, participando da mesma fantasia que ele. Talvez essa tenha sido a representação de que a mãe pode, finalmente, compreender os sentimentos e os desejos de seu filho, já que no momento em que ela volta à realidade, ela diz a ele que "sempre será seu filho”. Essa cena pode dar idéia ao espectador de que independentemente de qualquer atitude de Ludovic, ainda que compreendida como desviante pela família, o sentimento de amor a ele prevalecerá na relação maternal. Seria esse amor a prova do reconhecimento da diversidade? Ou seria esse amor a prova do amor 
materno incondicional que sobrepõe ao sujeito filho o sentimento amoroso, embora a concepção normativa da mãe não deixe de entendê-lo como “atípico”.

\section{Considerações finais}

Existem muitos filmes com diferentes narrativas sobre gênero e sexualidade, os quais envolvem os espectadores, em diferentes histórias estetizadas sobre a realidade dessa temática, que levantam muitas discussões em torno do que é consentido ou não pelas normas sociais. Este filme, em especial, abrange questões especificas sobre gênero, envolvendo a formação da sexualidade infantil, bem como o conflito entre as expectativas dos pais e adultos em choque com a diversidade. Dessa maneira, abrange a temática de modo a explicitar o sofrimento e os conflitos de uma criança, o pequeno Ludovic, que se sente diferente de seu sexo biológico e que age de acordo com essa diferença. Também explicita a dor e os conflitos da família dele, que não compreendem e nem buscam compreender as atitudes “destoantes” do garoto.

O modo como o filme vai se desenvolvendo envolve o espectador, sensibilizando-o o que possibilita despertar entre pais e mães, professores e professoras, adolescentes, estudantes, etc., sentimentos, questionamentos e reflexões frente a uma história que angustia e que traz a tona questões sobre a sexualidade infantil e a importância de estar preparado para lidar com o diálogo infantil. Nesse sentido, o filme pode se tornar um instrumento pedagógico importante, pois partindo da sensibilização pelo sofrimento da personagem e de seus familiares, pode-se pensar em trabalhar a dificuldade que é lidar com nossas próprias concepções estereotipadas de gênero, por meio de uma discussão reflexiva e dialogada, levando em conta a história e as experiências particulares de cada espectador.

O filme, então, suscita a reflexão e a possibilidade de questionar os padrões e reconhecer a diversidade, podendo ser utilizado com o trabalho de orientação afetivo-sexual junto a pais e familiares, a estudantes, a professores, a educadores em geral, que se interessam em refletir sobre a sexualidade humana, de uma maneira não cristalizada, a fim de não reproduzir os estereotipados repassados pela sociedade em geral. A partir dos aspectos teóricos como a sexualidade na infância e questões de gênero, a análise sobre a narrativa do filme pode ser um recurso pedagógico importante no campo da educação e da orientação sexual. 


\title{
GENDER IN CHILDHOOD: ANALYSIS OF THE FILM "LA VIE IN ROSE" AS TEACHING TOOL IN SEXUAL EDUCATION
}

\begin{abstract}
The aim of this study was analyze the issues of gender in children's sexuality through the media narrative of the film La Vie in Rose, which has the themes of transsexual, homosexual, identity of gender, family and social discrimination. From the theoretical issues of sexuality in childhood and the construction of gender, using the content analysis, was elected in the narrative of the film the following categories to discussion: (a) sexual identities: the male and female, (b) the gender pathological and heteronormativity, (c) sex education by the family and the socialization sexist and (d) the preconception to sexual diversity. The way that the film shows these issues can take the viewer to questions and reflections about the subject. Accordingly, the analysis of the film can be used as a teaching tool for educators who desire reflect critically on issues relating to human sexuality in sexual education.
\end{abstract}

KEYWORDS: Gender. Child sexuality. Teaching resource.

\section{REFERÊNCIAS}

ÁRAN, M. A transexualidade e a gramática normativa do sistema sexo-gênero. Ágora, Rio de Janeiro, v.9, n.1, p.49-63, jan/jun. 2006.

BARDIN, L. Análise de conteúdo. Lisboa: Edições 70, 1977.

BONETTI, A. L. Entre femininos e masculinos: negociando relações de gênero no campo político. Cadernos Pagu, São Paulo, n.20, p.177-203, 2003.

CARLOTO, C. M. O conceito de gênero e sua importância para a análise das relações sociais. Serviço Social em Revista, Londrina, v.3, n.2, jan/jun 2001. Disponível em: <http://www.ssrevista.uel.br/c_v3n2_genero.htm>. Acesso em: 18 maio 2008.

FERNANDES, W. R.; SIQUEIRA, V. H. F. Cinema e relações de gênero: ouvindo mulheres idosas. In: REUNIÃO ANUAL DA ASSOCIAÇÃO NACIONAL DE PESQUISA E PÓSGRADUAÇÃO EM EDUCAÇÃO, 29., 2006, Caxambú. Anais... Caxambu: ANPED, 2006. Disponível em: < http://www.anped.org.br/reunioes/29ra/trabalhos/trabalho/GT23-2327-Int.pdf $>$. Acesso em: 18 maio 2008.

GOFFMAN, E. Estigma: notas sobre a manipulação da identidade deteriorada. Rio de Janeiro: Guanabara, 1988. 
LOURO, G. L. (Org.). O corpo educado: pedagogias da sexualidade. Tradução de Tomaz Tadeu da Silva. Belo Horizonte: Autêntica, 1999.

MAIA, A. C. B. Sexualidade: reflexões sobre um conceito amplo. SBPN Scientific Journal, [S.l.], v.5, n.1, p.45-48, 2001.

MAIA, A. C. B.; MAIA, A. F. (Org.). Sexualidade e infância. Bauru: Faculdade de Ciências; Brasília: MEC:SEF, 2005. (Cadernos CECEMCA, n.1).

RAMSEY, G. Transexuais: perguntas e respostas. São Paulo: Summus, 1998.

RINALDI, D.; BITTENCOURT, V. B. O transexualismo e a questão da identidade. Rio de Janeiro, 2003. Disponível em:

$<$ http://www.interseccaopsicanalitica.com.br/biblioteca/pdf/art145.pdf>. Acesso em: 19 nov. 2008.

SAFFIOTI, H. I. B. Rearticulando gênero e classe social. In: COSTA, A.O.; BRUSCHINI, C. (Org.). Uma questão de gênero. Rio de Janeiro: Rosa dos Tempos, 1992.

VIEIRA, T. R. Mudança de sexo: aspectos médicos, psicológicos e jurídicos. São Paulo: Santos Editora, 1996.

VERDE, J. B.; GRAZIOTTIN, A. Transexualismo: o enigma da identidade. São Paulo: Paulus, 1997. 